\title{
Resiliencia Urbana: Dinámicas y estrategias ecosistémicas para el desarrollo sustentable del hábitat local. Un caso de estudio: CABA Sur.
}

\author{
F. Pini, R. Ferraro y S. Lanari \\ Con la participación de los alumnos MP. Lauletta, B. López Kaseb y P. Quiles \\ Instituto de investigaciones del hábitat y el medio ambiente. \\ Facultad de Arquitectura, Diseño, Arte y Urbanismo. Universidad de Morón. \\ E-mail: fpini@unimoron.edu.ar; fopini@yahoo.com.ar
}

\section{Resumen}

La resiliencia es la capacidad de un sistema complejo de absorber perturbaciones, reorganizarse y ajustarse, a la vez que mantiene su funcionalidad e identidad, mediante un equilibrio dinámico. Si bien es un término con historia, su teoría actual tuvo orígenes en la ecología. El primer investigador en asociarla a los sistemas ecológicos y sociales fue C.S. Holling en 1973. El concepto ha comenzado a usarse en procesos más complejos que los naturales, como los de la acción humana, la escala espacial, temporal y social aplicándose cada vez más en ámbitos como: manejo de riesgos, adaptación al cambio climático, sistemas de energía y desarrollo urbano. En este marco, el concepto de resiliencia aplicados en términos de ciudad, puede definirse como aquella capacidad que tienen los eco-sistemas urbanos -o mejor aún, sus gestores- de anticipar eventos que afectarán la dinámica urbana; y de cómo las implicaciones de ciertos factores económicos, sociales o culturales de dicha dinámica transferirán a la ciudad elementos que le permitan responder a las adversidades que se pueden presentar en el proceso de gestión urbana. La ONU, el Banco Mundial, el BID, la OCDE, entre otros, investigan y desarrollan programas sobre este tema. En 2002, se creó el programa ONU-Hábitat y en 2013, 100 Resilient Cities -Fundación Rockefeller- como apoyo a gobiernos locales. En 2016, Bs. As. fue integrada a la red. A su vez, la UM-
FADAU ha firmado un Convenio con la Secretaría de Hábitat y Desarrollo Urbano de la CABA para llevar a cabo acciones conjuntas de cooperación, académicas y de servicio, a desarrollar en la zona sur de la misma, la más postergada, que posee serias problemáticas sociales -asentamientos marginales- ambientales, de organización urbana y de necesidad de revitalización de sus actividades, siendo ambas circunstancias, oportunidades para integrar teoría y práctica de la resiliencia urbana

Palabras clave: resiliencia urbana, desarrollo local sustentable, CABA sur

\section{Justificación}

Más del $50 \%$ de la población mundial es urbana. En el año 2030 se espera que 5000 millones de personas vivan en ciudades. En ese mismo período se predice que el volumen construido sobre la Tierra, se duplicará. Ese crecimiento producirá demandas cada vez mayores sobre los servicios prestados por los eco-sistemas locales y globales. Sin embargo, el Programa de Evaluación de EcoSistemas del Milenio -NU- concluyó recientemente que los servicios ambientales proporcionados por los ecosistemas están disminuyendo a un ritmo alarmante, ejerciendo una presión tal sobre el medio ambiente, que la capacidad de los eco-sistemas para soportar a las generaciones futuras 
ya no puede darse por sentado. Tales servicios ambientales constituyen todos los bienes y servicios que los sistemas naturales aportan y de los que el bienestar social y el desarrollo económico dependen (Fomento, 2008)

En este marco, el concepto de resiliencia aplicado en términos de ciudad, puede definirse como aquella capacidad que tienen los eco-sistemas urbanos -0 mejor aún, sus gestores- de anticipar eventos que afectarán la dinámica urbana; y de cómo las implicaciones de ciertos factores económicos, sociales o culturales de dicha dinámica, trasferirán a la ciudad elementos que le permitan responder a las adversidades que se puedan presentar en el proceso de gestión urbana (Ultramari y Denis, 2007, en Mallqui, op cit). La resiliencia tiene que ver también, con las oportunidades que proporcionará una perturbación, en términos de recombinación de estructuras y procesos de evolución, renovación del sistema y aparición de nuevas trayectorias.

Es así que el conocimiento de la resiliencia es fundamental para la teoría y práctica del urbanismo y el desarrollo sustentable, en primer lugar, por cuestionar el modo habitual de entender los procesos naturales y las interacciones hombre-naturaleza, mejorando la comprensión de las dinámicas entre sistemas. En segundo lugar, explorando nuevas formas de gestionar el cambio, la incertidumbre y la transición hacia la sostenibilidad. Para ello es necesario aumentar la comprensión de los factores y dinámicas socio-ecológicas que sustentan la resiliencia urbana y de las prácticas para la integración de los servicios ecosistémicos con la organización del territorio, así como identificar principios y reglas generales, útiles para la planificación de tales servicios, la promoción del desarrollo urbano sostenible y la exploración de nuevos modelos y herramientas para la gestión urbana, el diseño innovador de proyectos urbanos complejos y el desarrollo de ciudades más resilientes (Fomento, op cit)

Desdeel punto de vistade la aplicación operativa del concepto, en 2016 la Ciudad de Buenos Aires fue seleccionada como una de las 100 Resilient Cities, e incorporada a la red, para recibir apoyo y desarrollar estrategias de resiliencia para afrontar los desafíos sociales, físicos y económicos. A su vez, la UM-FADAU ha firmado un Convenio con la Secretaría de Hábitat y Desarrollo Urbano de la CABA para llevar a cabo acciones conjuntas de cooperación, académicas y de servicio, a desarrollar en la zona sur de la misma, la más postergada, que posee serias problemáticas sociales -asentamientos marginales- ambientales, de organización urbana y de necesidad de revitalización de sus actividades, siendo ambas circunstancias, oportunidades para integrar teoría y práctica de la resiliencia urbana

\section{Marco Teórico}

Las sociedades han evolucionado adaptándose a los condicionantes del medio, adaptando el medio a sus propias necesidades, adoptando elementos de resistencia, creando y reinventándose para poder sobrevivir y sobreponerse ante situaciones límite. En nuestros días, la crisis multidimensional (ecológica, social, energética, económica) se manifiesta singularmente en los ambientes urbanos. El concepto de resiliencia y sus estrategias (diversidad, capacidad de aprendizaje, innovación y adaptación, auto organización y autosuficiencia) pueden aportar pautas para reducir la vulnerabilidad urbana ante escenarios futuros desfavorables (Ovacen, 2010).

La resiliencia está intrínsecamente vinculada y complementa al concepto de sostenibilidad porque, más que un estado fijo ideal, los procesos sostenibles están definidos por la trayectoria de equilibrios dinámicos y adaptación al cambio, y al igual que en ellos, la resiliencia urbana comparte la necesidad de un enfoque eco-sistémico holístico (Morato, 2015)

En investigaciones anteriores de este grupo, siguiendo a Boisier (2002/04), se expresaba que el desarrollo debía interpretarse como una emergencia sistémica de un sistema territorial complejo, dinámico, adaptativo, sinergizado y organizado, siendo la variedad la medida de su complejidad, destacándose la no linealidad de los procesos, sino su forma evolutiva (Byrne, 1998). Dependiendo de la conectividad entre factores y procesos de menos escala sinápsis- requiere que se construya una red interactiva de alta densidad por donde fluya información -sinergia-, y que se introduzca energía impulsora al sistema -socialización de conocimientos-. Y es así que existe una interacción dinámica permanente entre la necesidad autopoiética de conservar la identidad y la necesidad vital de cambiar, de crecer, de explorar. Siendo un sistema adaptativo complejo, aprende a la vez que se autoorganiza. El desarrollo es 
entonces, el resultado de la adaptación interactiva con el entorno, producto de subsistemas interdependientes que buscan mejorar su situación y alcanzar objetivos cualitativos y de bienestar espiritual. Si en los espacios territoriales pertinentes, se logra aglutinar pensamiento complejo, conocimiento, acción común y poder político, el desarrollo surgirá como una propiedad de un sistema sociotecno-económico territorializado, a partir del cual habrá que encauzarlo para lograr una diseminación territorial justa, eficiente y respetuosa del entorno (Boisier, op. cit.)

A estos conceptos, la resiliencia urbana incorpora, además, estudios de enfoque prospectivo y la consideración del riesgo y la incertidumbre para disminuir la vulnerabilidad urbana. En suma, es tanto adaptativa (recuperarse y resurgir) como transformativa (mejorar y repuntar). Es la integración de un conjunto de capacidades y recursos que ayudan a identificar los riesgos y las vulnerabilidades más urgentes para abordarlos de formas estratégicas y creativas, pudiendo utilizarse como un marco conceptual para el desarrollo urbano (Noguera, 2015)

La resiliencia es un tema transversal que abordado de manera coherente e integral puede reducir y reorientar las inequidades sociales, económicas y ambientales en áreas urbanas. De este modo, es tanto un protector de los beneficios del desarrollo como un conducto para el desarrollo sostenible futuro (Diálogo 5, 2013)

Sin embargo, existen desafíos y consideraciones que la resiliencia debe afrontar: Debe ser local, reconoce los riesgos, requiere participación, enfrenta resistencia, no se obtiene de inmediato, es compleja (Idea, op cit). A su vez, ONU-Hábitat y el Programa 100 Resilient Cities, enuncian indicadores de resiliencia urbana, a tener en cuenta en el desarrollo del PID, así como experiencias prácticas de ciudades que iniciaron el proceso.

Respecto a la Zona Sur de la CABA, existen antecedentes y documentación actual de gestión territorial, estudios y programas urbanos, así como aportes que serán referentes del PID

Formulación del Problema - Preguntas de Investigación Los asentamientos humanos sufren impactos y tensiones de diferente escala en distintos momentos de su existencia. Los impactos agudos son eventos disruptivos que ocurren repentinamente, como inundaciones, fallas de infraestructura, colapso del sistema de transporte, etc, mientras que las tensiones crónicas, hacen referencia a factores que generan presión y debilitan a la ciudad de manera cíclica, como el déficit en vivienda y equipamientos, desigualdad, desintegración urbana y social, disminución de los servicios ambientales, etc.

Tanto los impactos como las tensiones crónicas, ya sean generados por razones naturales 0 humanas, suelen traslaparse y estar interconectados, haciendo que las acciones de respuesta sean más complejas y necesarias, requiriendo un abordaje holístico de sus causas, más que responder exclusivamente a sus consecuencias (Idea, op. cit) Las ciudades y los gobiernos locales se ven obligados a incrementar su capacidad para reducir la existencia de situaciones negativas, así como el período de recuperación ante ellas, por lo que se hace necesario contar con nuevas herramientas y enfoques para una mejor protección de los habitantes y de los recursos económicos y naturales de nuestros pueblos y ciudades (ONU-Hábitat)

En consecuencia, ciudades de todo el mundo están iniciando su camino para convertirse en resilientes. La toma de conciencia suele ir precedida de alguna crisis o conflicto que afecte a la población, a sus bienes 0 a sus servicios. Cuando esto ocurre, las ciudades descubren que son vulnerables, especialmente los grupos sociales postergados, y que necesitan mejorar su capacidad de actuación y recuperación (Noguera, op cit)

Así, los problemas a resolver pueden clasificarse según categorías de Riesgos: Riesgos naturales ecosistémicos -degradación de ecosistemas y pérdida de servicios ambientales-. Riesgos tecnológicos ligados a la producción y utilización de energía-. Riesgos sociales -ligados a la inequidad y exclusión-. Riesgos económicos -ligados a la ineficiencia, escasez y despilfarro de recursos, modelos insostenibles de producción y consumo-. Riesgos de gestión urbana -ligados a fallas en la gestión del desarrollo local y de los canales de participación-. Así como Riesgos biosanitarios. (Mallqui, op cit)

Específicamente, el área de estudio conforma parte del límite sur de la CABA, caracterizado por el accidente físico natural que configura el curso contaminado del Riachuelo. Se constituye en un área intersticial, con zonas 
inundables, atravesada por corredores de transporte N-S que no han colaborado en su configuración. Presenta zonas desactivadas por obsolescencia funcional con degradación urbana y ambiental. Es el ámbito de mayor localización de villas de emergencia en terrenos vacantes con un hábitat en condiciones comprometidas. Con alta densidad de vías férreas, grandes predios subutilizados, coexistencia de actividad residencial de baja densidad con industrias, zonas industriales de baja 0 nula actividad, diversidad de tipologías y calidades de vivienda. En síntesis, degradación del hábitat, marginación social, desintegración territorial, vulnerabilidad, estancamiento económico.

\section{Preguntas de Investigación}

¿Cuáles son y cómo operan los factores socio-ecológicos que sustentan la resiliencia urbana?

¿Cómo se articula la resiliencia urbana con los procesos de desarrollo local sustentable?

¿Cuál es el diagnóstico y el perfil de resiliencia del área sur de CABA?

¿Qué oportunidades de desarrollo transformacional sostenible pueden identificarse a partir del conocimiento del riesgo y la vulnerabilidad?

¿Qué recomendaciones y estrategias integradas de resiliencia urbana pueden enunciarse, focalizando en los riesgos socio-ecosistémicos y de gestión del desarrollo local?

\section{Objetivos}

Indagar en el concepto de resiliencia urbana y comprender los factores socio-ecológicos que la sustentan.

Identificar y articular resiliencia urbana y desarrollo urbano sustentable

Elaborar estratégias integradas de resiliencia urbana

Elaborar un diagnóstico y un Perfil de Resiliencia para el Área Sur de la CABA, que coadyuve y brinde oportunidades para su desarrollo transformacional sostenible

Elaborar recomendaciones y estrategias integradas de resiliencia urbana según categorías de riesgos, focalizando en los socio-ecosistémicos y los de gestión del desarrollo local.

\section{Hipótesis de la Investigación}

H1.- La integración de estrategias de resiliencia urbana con las de desarrollo sustentable del hábitat local, potencian y aceleran las dinámicas transformacionales de recuperación, revitalización y cualificación de las condiciones socioecosistémicas locales.

H2.- La caracterización del área sur de la CABA posibilita la definición de un perfil de resiliencia propio que coadyuve y brinde oportunidades para su desarrollo transformacional sostenible

H3.- El elevado peso relativo de los riesgos socioecosistémicos direcciona la definición de estrategias para la gestión del desarrollo transformacional sostenible.

\section{Metodología de Trabajo}

El estudio propuesto es una investigación aplicada que presenta un enfoque cualitativo interpretativo y que utilizará técnica documental y de campo, mediante revisión bibliográfica y el estudio del área sur de la CABA. Se asumirá un enfoque sistémico sostenido en métodos, técnicas y procedimientos que responden a los campos disciplinares implicados en el estudio de las variables de análisis urbanas y socio-ecológicas.

\section{Resultados Esperados}

Elaboración de un modelo referencial que, a modo de recomendaciones y estrategias integradas de resiliencia urbana coadyuven al desarrollo transformacional sostenible del hábitat local y, consecuentemente, a la creación de mejores condiciones de vida para sus comunidades, facilitando respuestas para sus necesidades y demandas.

Los resultados de la presente investigación serán una guía para la definición de políticas públicas y para la gestión de la resiliencia urbana integrada al desarrollo transformacional sostenible.

\section{Bibliografía}

- Boisier, Sergio. (2004). El desarrollo territorial a partir de la construcción de capital sinergético.

- CIPPEC, programa de ciudades (2017). Resiliencia 
urbana. Diálogos institucionales. En https://www.

urbana-el-salvavidas-de-las-ciudades cippec.org/wp-content/uploads/2017/03/980-pdf

- Diálogo 5. http://mirror.unhabitat.org/downloads/docs/ Dialogo_5.pdf

- Fundación Idea (2017). Resiliencia urbana en América Latina: Una guía para autoridades locales

- Gobierno de la CABA. La resiliencia urbana. Buenos Aires Resiliente. En https://www.buenosaires.gob. ar/jefedegobierno/secretariageneral/que-es-laresiliencia-urbana

- Gobierno de la CABA. Plan de ordenamiento urbano de la CABA. Plan Urbano-Ambiental CABA.

- Mallqui, Aníbal. (2013). ¿Resiliencia urbana o ciudades resilientes? En https://www.amallqui.files.wordpress. com/2013/04/articulo_resiliencia.pdf

- Martínez Gaete, Constanza. (2014). 10 factores que hacen que una ciudad sea resiliente. En revista Plataforma Urbana del 11/07/2014. http://www. plataformaurbana.cl/archive/2014/07/11/10-factoresque-hacen-que-una-ciudad-sea-resiliente/

- Ministerio de Fomento. (2008). Super. Planificación de ciudades sostenibles desde los servicios ambientales proporcionados por los ecosistemas y la resiliencia. España. https://www.fomento.gob.es/super.htm

- Noguera, G (ONU-Hábitat). (2015). La resiliencia urbana. Clave de del futuro de las ciudades. En el País Digital https://elpais.com/elpais/2015/05/21/planeta_ futuro/1432231832_145438.html.

- ONU-Hábitat (2017). Resiliencia. En https:// es.unhabitat.org/temas-urbanos/resiliencia/

- Ovacen. Resiliencia y el concepto de adaptación. https://ovacen.com/resiliencia-y-el-concepto-deadaptacion/

- Schuschny, Andrés. (2014). Sostenibilidad y resiliencia urbana. CEPAL-ONU. ONU-Hábitat

- Velasco, Andrea. (2017). Resiliencia urbana, el salvavidas de las ciudades. http://www. futurosostenible.elmundo.es/resiliencia/resiliencia- 